\title{
HIGIENIZADOR ECO-MÃOS: PROJETO DE DESENVOLVIMENTO DE UMA PIA AUTOMÁTICA PORTÁTIL
}

Aline Soares Pereira (pereira.asp@gmail.com) - Universidade Federal de Pelotas, (UFPel).

Ariane Ferreira Porto Rosa (afprosa61 @ gmail.com) - Universidade Federal de Pelotas, (UFPel).

Elmer Alexis Gamboa (elmeralexis@ gmail.com) - Universidade Federal de Pelotas, (UFPel).

Elka Carolina Ojeda (ojedaelka@ gmail.com) - Universidade Federal de Pelotas, (UFPel).

Vanderson Volz (vanderson.94@ hotmail.com) - Universidade Federal de Pelotas, (UFPel).

\section{RESUMO}

As mudanças que foram impostas à humanidade a partir do surgimento do coronavírus (Covid-19), proporcionaram uma urgência pela busca de soluções em termos de produtos e tecnologias para ajudar a mitigar a disseminação do vírus. Neste sentido, as universidades e centros de pesquisa têm um papel importante na criação dessas novas alternativas e soluções. Um dos protocolos para evitar a propagação do vírus é relativa a necessidade das pessoas realizar a higienização das mãos de forma adequada. Portanto, nesse cenário, ocorreu a motivação de professores, alunos e servidores do Centro de Engenharias (CEng) da Universidade Federal de Pelotas para propor um protótipo inicial de uma pia portátil, semelhante a que estava sendo projetada na Universidade Federal de Rio Grande (FURG). O produto proposto pela comunidade acadêmica, conta com a automação necessária para detectar a chegada de usuário e o acionamento automático de saída de sabão e água, esse executa uma sequência de etapas de higienização e guia aos usuários no processo através de sinais visuais. Neste presente artigo apresenta-se a metodologia para a construção do produto utilizada e os resultados obtidos partindo do conceito inicial até sua implementação.

Palavras chave: inovação; produto sustentável; projeto produto; coronavírus; soluções sustentáveis.

\section{INTRODUÇÃO}

Segundo Conselho de Enfermagem (COFEN, 2021) coronavírus é uma família de vírus que causam infecções respiratórias. O novo agente do coronavírus foi descoberto em 31/12/19 após casos registrados na China. Este agente infeccioso, provoca a doença chamada de 
coronavírus (Covid-19). Os primeiros coronavírus humanos foram isolados pela primeira vez em 1937. No entanto, foi em 1965 que o vírus foi descrito como coronavírus, em decorrência do perfil na microscopia, parecendo uma coroa. No Brasil foi confirmado o primeiro caso de coronavírus dia 26 de fevereiro de 2020 em São Paulo. A partir dessa primeira confirmação surgiram muitas iniciativas de todas as áreas da educação, da ciência e tecnologia para criar soluções imediatas que auxiliaram na mitigação da expansão do vírus. Estudos e inventos geraram novos serviços e produtos, todos com esforço de melhorar as condições sanitárias para prevenção da propagação da doença. Dentre das bases de conhecimento público de saúde geradas a partir da nova doença, destaca-se que uma das maneiras mais eficientes de prevenir a disseminação da doença é a lavagem adequada das mãos. Nesse sentido, para apoiar ações de forma a combater o avanço da pandemia do coronavírus (Covid-19), elaborou-se o projeto de produto chamado "Eco-mãos" que consiste em uma pia portátil ecológica e automatizada. Esse projeto foi estabelecido a partir de um protótipo inicial existente na Universidade Federal de Rio Grande (FURG), com adaptações à realidade da Universidade Federal de Pelotas (UFPel). O produto proposto pelo Centro de Engenharias (CEng) conta com a instrumentação eletrônica necessária, assim como e algoritmos computacionais que permitem realizar o processo de higienização de forma automática e sequencial, informando através de sinais visuais o início e finalização do tempo de execução cada etapa de higienização, o volume de sabão e/ou produto de desinfeção, o tempo adequado para ensaboar e esfregar as mãos, e fornecimento de volume de água potável adequado para lavagem de mãos. Desta forma, atendendo as recomendações da área da saúde no tempo e forma de execução de cada etapa de higienização. Percebida a necessidade de tornar a higienização um hábito, espera-se ampliar as ações na área de educação para saúde, fazendo com que as pessoas realmente incorporem no seu dia a dia esse costume de lavar as mãos. A motivação da proposta ocorreu de uma necessidade de poder contribuir com a demanda de oportunizar aos locais públicos um equipamento de fácil acesso e uso para que ocorra essa higiene de forma constante e habitual. Esse equipamento deverá ser disposto em espaços onde há circulação de muitas pessoas como paradas de ônibus, praças e parques, escolas, hospitais, centros comerciais entre outros.

\section{REVISÃO TEÓRICA}

\subsection{Inovação e o desenvolvimento de produtos}

O Desenvolvimento de Novos Produtos (DNP), que visa atender às necessidades dos clientes, é uma atividade estratégica para a sustentabilidade organizacional (econômica, social e 
ambiental). Os estudos DNP normalmente focam em fatores organizacionais, como trabalho em equipe, integração multifuncional, comunicação interna / externa dentro das equipes, desempenho, processos e liderança de projeto (IGNATIUS et al., 2012).

Segundo Salerno (2017, p.80) é preciso distinguir inovação de invenção.

\begin{abstract}
"Invenção é a criação de um construto físico ou intelectual. Pode envolver um protótipo, uma fórmula. Santos Dumont foi um inventor importante - inventou o avião, o relógio de pulso. A uma invenção pode ser solicitada patente, para proteger os direitos de seu criador numa eventual exploração. Mas invenção não é sinônimo de produto transacionável no mercado. Já inovação é um conceito econômico, com validação social. Genericamente, algo novo que gere ou impacte negócios. Assim, a inovação, na nossa sociedade, se realiza no mercado, e o agente da inovação é a empresa - não é a universidade, não é o descobridor, não é o inventor. Santos Dumont, para ser um inovador, precisaria ter levado suas invenções ao mercado, coisa que outros fizeram. O computador pessoal só se tornou uma inovação quando foi criada uma empresa para produzi-lo e comercializá-lo. Assim sendo, discutir inovação implica, entre outros, discutir condições de produção e de mercado."
\end{abstract}

Para Proença et al., (2015) o processo de inovação pode ser visto em três grandes fases: ideação, desenvolvimento e difusão. Na primeira fase está o desenvolvimento do conceito ou scoping, na segunda fase a validação do conceito ou bussiness case, ou seja, nesta segunda fase a equipe multidisciplinar tem um número de ideias implantadas que podem gerar receita em um tempo de espera remoto até obter os testes e validação da ideia e, por última a terceira fase o lançamento com o retorno do investimento.

Enquanto que, Arruda (2017), expõe a inovação desde um ponto de vista social. Ou seja, as ideias baseadas no plano com um propósito específico de criar e desenvolver design sociais e de inovação social, com a finalidade de ser um agente vanguardista em uma sociedade sustentável que seja capaz de projetar inovações para necessidades presentes e com a suficiente visibilidade nas mudanças futuras. Isto é, a adição da viabilidade técnica e a necessidade socioeconômica e cultural.

De acordo com Etzkwitz e Zhou (2017) no modelo de gestão da inovação intitulado Tripla Hélice as interações universidade-indústria-governo, que formam uma "hélice tríplice" de inovação e empreendedorismo, são a chave para o crescimento econômico e o desenvolvimento social baseados no conhecimento.

Etzkwitz e Zhou (2017) afirmam que a análise clássica de relações triádicas recebe um molde institucional na Hélice Tríplice, em que a universidade, a indústria ou o governo atuam como um "tertius gaudens", instigando a inovação. Esse regime de inovação assume uma postura proativa na colocação do conhecimento em prática e na ampliação dos insumos que criarão o conhecimento acadêmico.

Este estudo está centrado na área de desenvolvimento de produto, integrando os conceitos de 
Invenção e Inovação no Desenvolvimento de Novo Produto. Assim, o desenvolvimento do produto pia portátil ecológica "Eco-mãos" pode ser classificado como um projeto de DNP desenvolvido no âmbito multidisciplinar universitário em IES pública federal, como uma invenção com potencialidades de inovação para o mercado brasileiro. Destaca-se que apesar de ter produtos semelhantes no mercado, estes foram projetados a partir da necessidade sanitárias preventivas frente a pandemia de Covid-19, temos um segundo desafio que é projetar um sistema para aproveitamento da água gerada após a higienização.

\subsection{Modelos de desenvolvimento de produtos}

Ao desenvolver um novo produto, raramente é possível verificar o cumprimento de todos os requisitos antes das etapas posteriores de desenvolvimento do produto, quando a prototipagem de exemplo e / ou teste físico é possível. No entanto, esse conhecimento é crucial, inclusive nas fases iniciais de desenvolvimento. Portanto, por meio da determinação do projeto do produto, as bases para o cumprimento dos requisitos podem ser fornecidas (KANDT et al., 2016).

A escolha das práticas de engenharia e design a serem implementadas durante o desenvolvimento do produto influenciam significativamente o sucesso ou o fracasso dos processos de inovação (ROSSI e TERZI, 2017). Dentre essas práticas, algumas são reconhecidas como promotoras da eficácia e eficiência do desenvolvimento de produtos, sendo, portanto, reconhecidas como as melhores práticas (KAHN et al., 2012).

Para melhorar a eficiência de um processo de desenvolvimento de produto é necessário que se crie padrões, padrões estes chamados de modelos ou metodologias de gestão do processo de desenvolvimento de produto, neles são descritas todas as etapas e cada atividade que será desenvolvida no processo.

Um dos modelos de PDP mais difundidos no país é do autor Rozenfeld et al. (2006). O modelo destes autores se divide em três macrofase: pré-desenvolvimento desenvolvimento e pós-desenvolvimento. E essas macrofase também são divididas em um total de nove fases, conforme Figura 1, sendo que tais fases são delimitadas por um conjunto de resultados que são avaliados nos pontos de checagem ao final de cada fase, ou seja, os "Gates". 


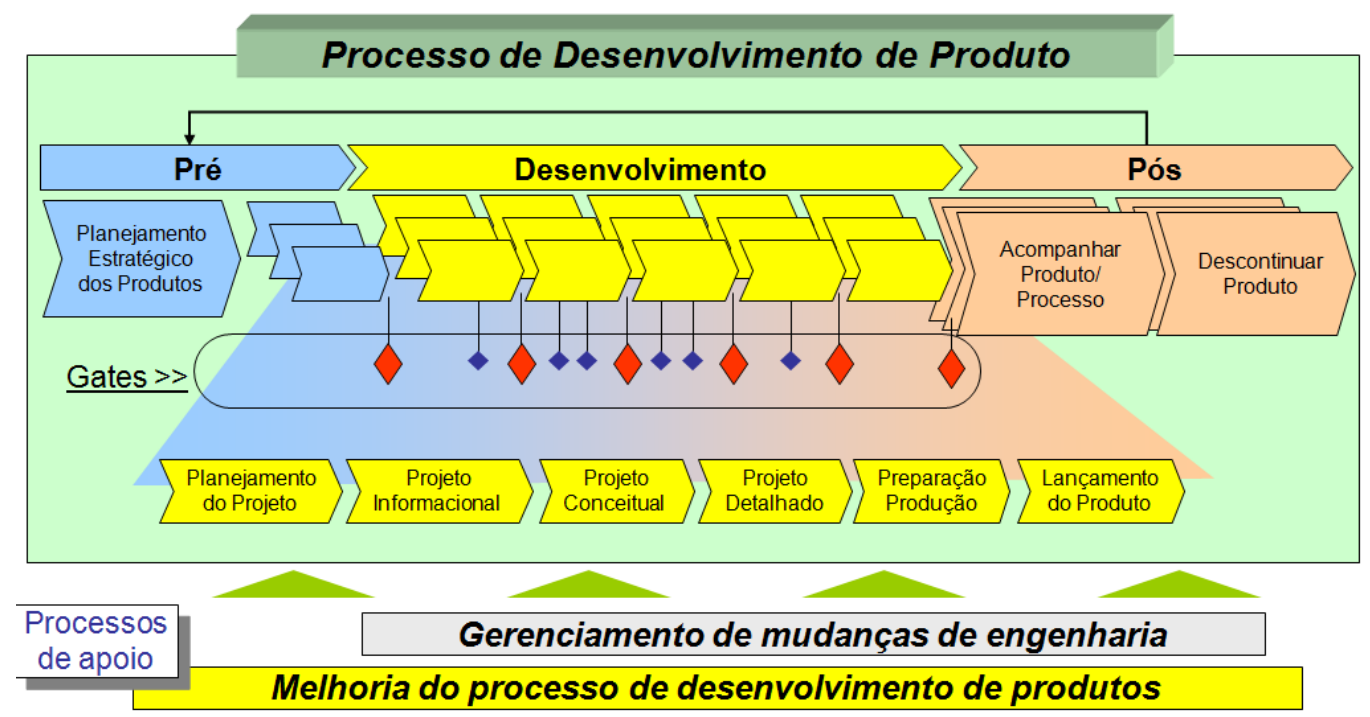

FIGURA 1 - Modelo de PDP. Fonte: Rozenfeld et al. (2006)

Rozenfeld et al. (2006) descrevem as fases do Processo de Desenvolvimento do Produto da seguinte maneira:

\section{Macro fase pré-desenvolvimento}

Planejamento Estratégico dos Produtos envolve as atividades de definição do projeto de desenvolvimento, realizada a partir da estratégia da organização, verificando possíveis restrições de recursos e conhecimento, informações sobre consumidores e tendências tecnológicas e mercadológicas.

\section{Macro fase desenvolvimento}

Planejamento do Projeto: trata do desenvolvimento de um produto em particular do portfólio de produtos da organização. A partir da escolha do projeto, se fazem necessários uma boa previsão e análise do seu escopo e risco, de modo, a prevenir problemas futuros.

Projeto Informacional: desenvolve-se um conjunto de informações, denominado especificações-meta do produto, as quais devem refletir as características que o produto deverá possuir para atender as necessidades dos clientes, de modo a orientar a geração de soluções, os critérios de avaliação e a tomada de decisões.

Projeto Conceitual: o produto é modelado funcionalmente e descrito de uma maneira abstrata, independentemente de princípios físicos. Define-se uma arquitetura que contém a estrutura do produto, define-se o plano macro de processo e monitora-se a viabilidade econômica.

Projeto Detalhado: desenvolver e finalizar todas as especificações do produto para então serem encaminhados à manufatura e às outras fases do desenvolvimento. 
Preparação Produção: esta etapa engloba a produção do lote piloto, a definição dos processos de produção e manutenção, ou seja, trata de todas as atividades da cadeia de suprimentos do ponto de vista interno, objetivando a obtenção do produto.

Lançamento do Produto: esta fase envolve o desenho dos processos de venda e distribuição, atendimento ao cliente, assistência técnica e as campanhas de marketing, ou seja, colocar o produto no mercado.

\section{Macro fase pós-desenvolvimento}

Acompanhar Produto/Processo: garantir o acompanhamento do desempenho do produto na produção e no mercado, identificando necessidades ou oportunidades de melhorias e garantindo que a retirada cause o menor impacto possível aos consumidores, organização e meio ambiente.

Descontinuar Produto: esta última fase acontece o recebimento do produto de volta, a descontinuidade da produção e a finalização da assistência técnica.

\section{METODOLOGIA}

A presente pesquisa é classificada como uma pesquisa exploratória e aplicada. Conforme Gil (2017), os estudos aplicados têm como escopo a utilização de toda informação disponível para a criação de novas tecnologias e métodos, transformando a sociedade atual em que vivemos. Esse tipo de pesquisa possui resultados mais palpáveis, muitas vezes, percebidos de forma direta pela sociedade.

A Figura 2 ilustra o delineamento metodológico o qual está baseado em quatro etapas principais de execução. Na primeira etapa se realizou um estudo sobre o protótipo inicial desenvolvido pela FURG, no caso uma pia portátil automática, as informações foram levantadas através de reuniões com professores e técnicos, atuantes na construção do protótipo, daquela universidade. Na segunda etapa foi elaborado um estudo de viabilidade técnica e econômica para produzir o protótipo. Através de uma primeira fase exploratória técnica e de engenharia, levantou-se os materiais e componentes necessários para a fabricação do sistema de higienização e os custos para ter o produto finalizado, ficando em cada unidade em torno de $\mathrm{R} \$ 650,00$ reais.

A etapa três tratou da fabricação do protótipo, foram realizadas parcerias com empresas Petrosul Comércio e Distribuição de Lubrificantes e Lubrisul Lubrificantes e Filtros do município de Rio Grande que doaram alguns tonéis. No município de Pelotas a indústria Freedom Veículos Elétricos LTDA fez a pintura destes tonéis e a empresa Bit Comunicação 
Visual Ltda a parte de adesivagem. O desenvolvimento dos dois primeiros protótipos contou com o apoio e trabalho de um grupo multidisciplinar de técnicos, docentes e discentes atuantes no Centro de Engenharias (CEng). Além disso, um discente do curso de design da UFPel elaborou o "slogan" para apresentação do produto.

Após o processo de fabricação dos sistemas foram realizados todos os testes para prever e prevenir possíveis falhas no sistema. A etapa quatro consistiu-se em selecionar um local para exposição do protótipo, no caso uma UBS (Unidade Básica de Saúde) e realizar o acompanhamento deste no dia a dia para avaliações.

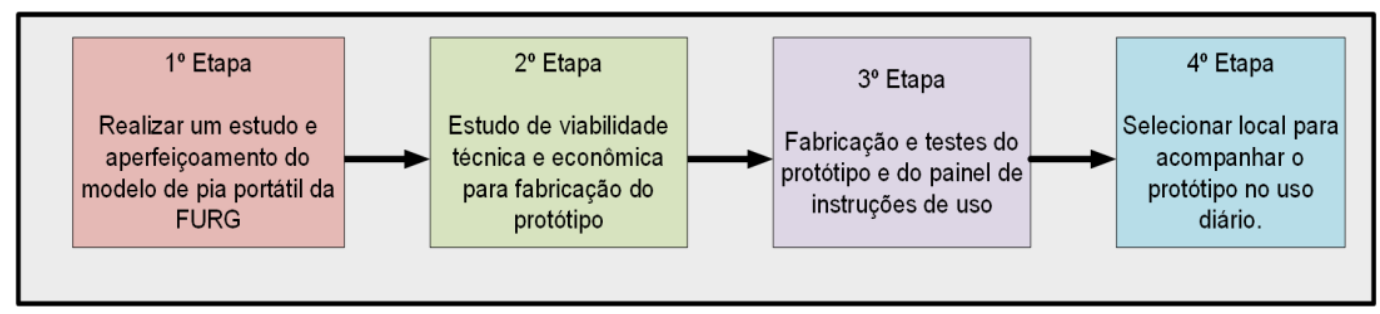

FIGURA 2 - Etapas do projeto. Fonte: Os autores

\section{RESULTADOS E DISCUSSÃO}

Os resultados das diferentes etapas de construção dos protótipos iniciais podem ser observados na Figura 3. Observou-se a necessidade de dividir o processo de construção a partir da experiência e conhecimento do conjunto de docentes, discentes e técnicos voluntários para a execução do projeto. No primeiro estágio de produção, foi realizado o corte dos tonéis metálicos reciclados, os quais servem como sustento inicial do sistema hidráulico (pia, torneiras e tanques) e os subsistemas de automação (sensores, atuadores, circuitos de potência e de controle). Esta primeira fase é importante, uma vez que se consideram fatores de desenho e ergonomia, a posição da torneira e pia, assim como a melhor posição dos sensores em relação aos possíveis usuários do sistema.

Depois de finalizada esta etapa, foi projetado o sistema de controle e automação do sistema. Assim, observou-se a necessidade de utilizar, como início de execução, um sensor de proximidade em conjunto com uma chave eletrônica (condicionada a um pedal) com a finalidade de assegurar a presença do usuário e eliminar qualquer ruído que ative o sistema e produza desperdício de água, sabão e/ou energia elétrica. Seguidamente, foi implementado uma válvula solenoide e uma bombas eletro-hidráulica como mecanismo de atuação para água e sabão, respectivamente. Adicionalmente, foi implementado um conjunto de LEDs que 
fornecem a informação de execução da entrada e saída de cada uma das etapas de higienização.

Estes dispositivos eletrônicos (sensores e atuadores) têm como plataforma de controle e comunicação uma placa PCB eletrônica desenvolvida e construída pelos estudantes atuantes no projeto, como ilustrado na Figura 3. O sistema eletrônico integrado está composto por uma parte de potência de alimentação e outra de acondicionamento de sinal e controle. Esta placa apossui como núcleo de processamento um processador ATmega328P® fornecido pela plataforma Arduino Uno R3®.

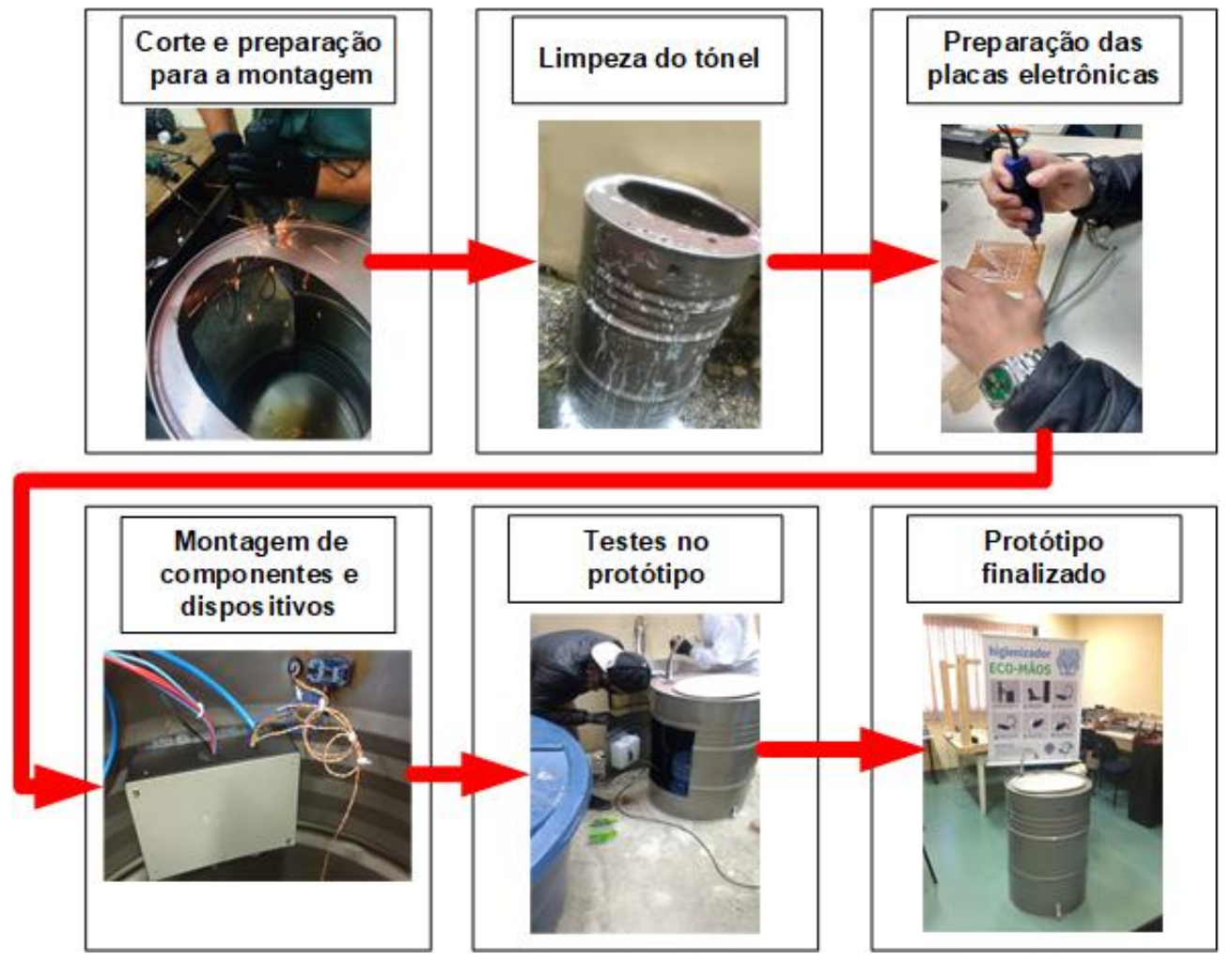

FIGURA 3 - Etapas para fabricação da pia. Fonte: Os autores

Foram desenvolvidas duas versões de higienizador, uma com encanamento de saída para o esgoto e encanamento de entrada da água potável externa, e outra sem encanamento que possui dois tanques internos e que foi projetada para ser utilizada como pia portátil. Finalmente, para os protótipos construídos a etapa de testes foi executada. Nesta etapa observou-se a necessidade de realizar ajustes ao sistema. Assim, foi realizada uma calibração no sensor de proximidade para monitorar distância máxima de $20 \mathrm{~cm}$ para o início da execução; também, foi observado a necessidade de ajustar o tempo de acionamento da bomba de sabão em função da sua viscosidade, isto é, maior viscosidade mais tempo de atuação e 
menor viscosidade menos tempo de atuação. A partir destes problemas identificados, observou-se a necessidade de realizar estes processos de calibração do sistema de automação e a programação de parâmetros de execução de forma particular para os futuros sistemas que serão desenvolvidos.

De outro lado, integrantes do grupo de trabalho encarregados da parte de desenvolvimento da identidade visual do sistema desenvolveram o Slogan e o logotipo que identifica o sistema, o qual pode ser observado na Figura 4. Este a parte conceitual do projeto como uma plataforma interativa e educativa. Este é um resultado importante, uma vez que identifica o sistema como uma ferramenta de higienização automática, interativa e educativa.

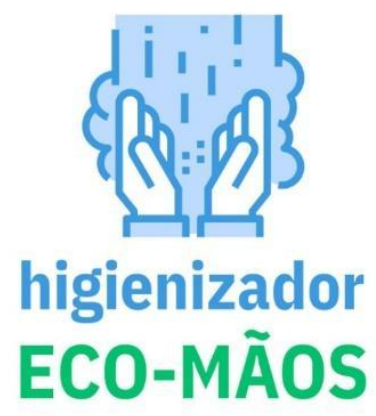

FIGURA 4 - Slogan para divulgação do projeto da pia portátil. Fonte: Os autores

Levando em consideração a quantidade total de equipamentos, materiais, fluxos de trabalho e controle de custos envolvidos no desenvolvimento da pia portátil, elaborou-se um manual técnico referente ao processo de produção do projeto, onde objetivou-se estabelecer as diretrizes básicas para a montagem e inspeção da pia portátil. Os fluxos dos processos relacionados as etapas de automação e fabricação da pia podem ser visualizadas, respectivamente, nas Figuras 5 e 6. A Figura 5 retrata o processo de automação da pia referente à versão sem encanamento. Para o processo de automação referente à versão com encanamento, deve-se desconsiderar o passo de "fixação da bomba d'água". 


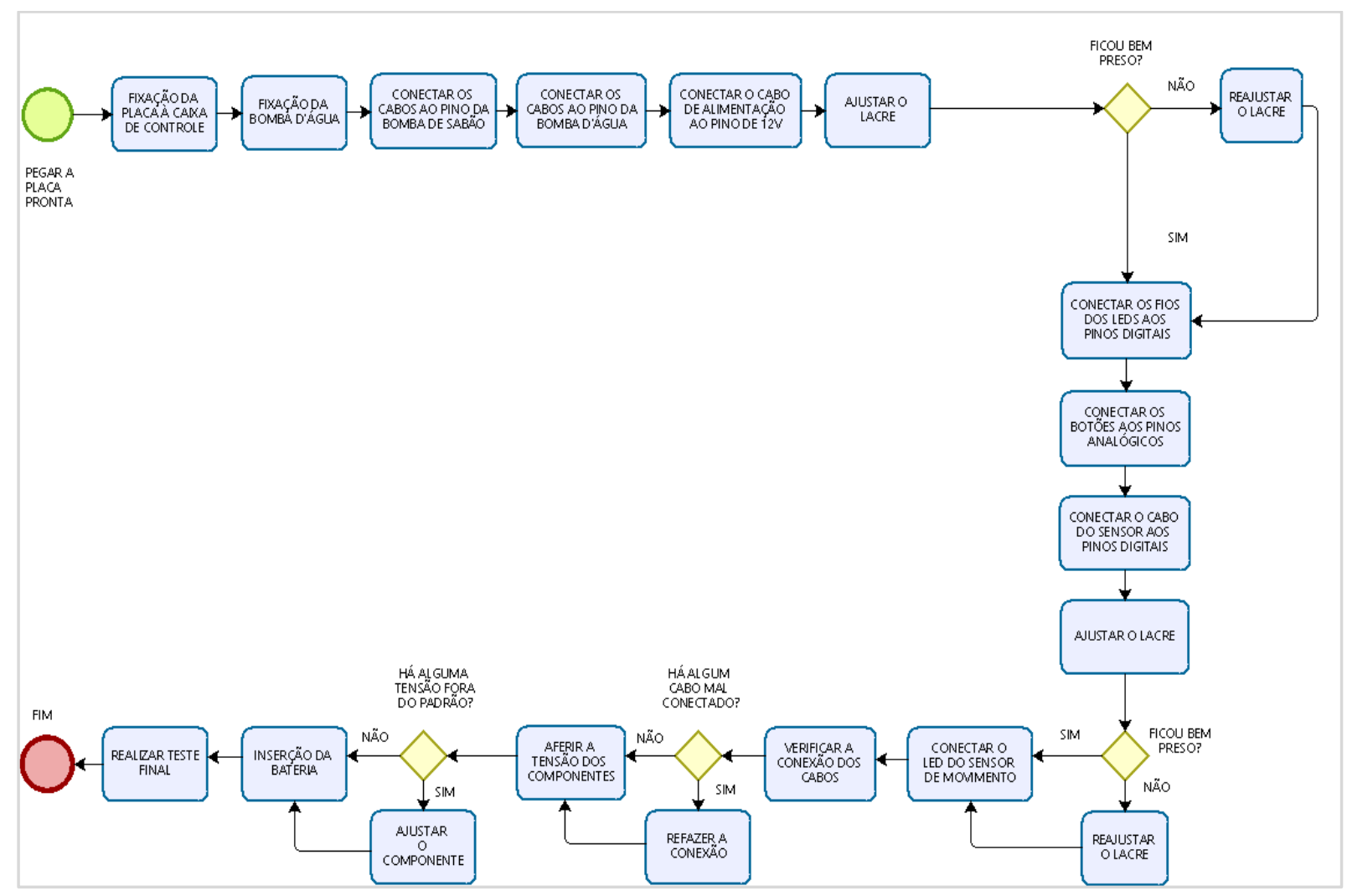

FIGURA 5 - Processo de automação. Fonte: Os autores

A Figura 6 apresenta o fluxo do processo de fabricação da pia através da versão sem encanamento. Para a versão com encanamento, deve-se acrescentar um passo chamado "Furo do cano de saída/entrada na parte traseira da pia”, que é realizado após o furo dos arrebites.

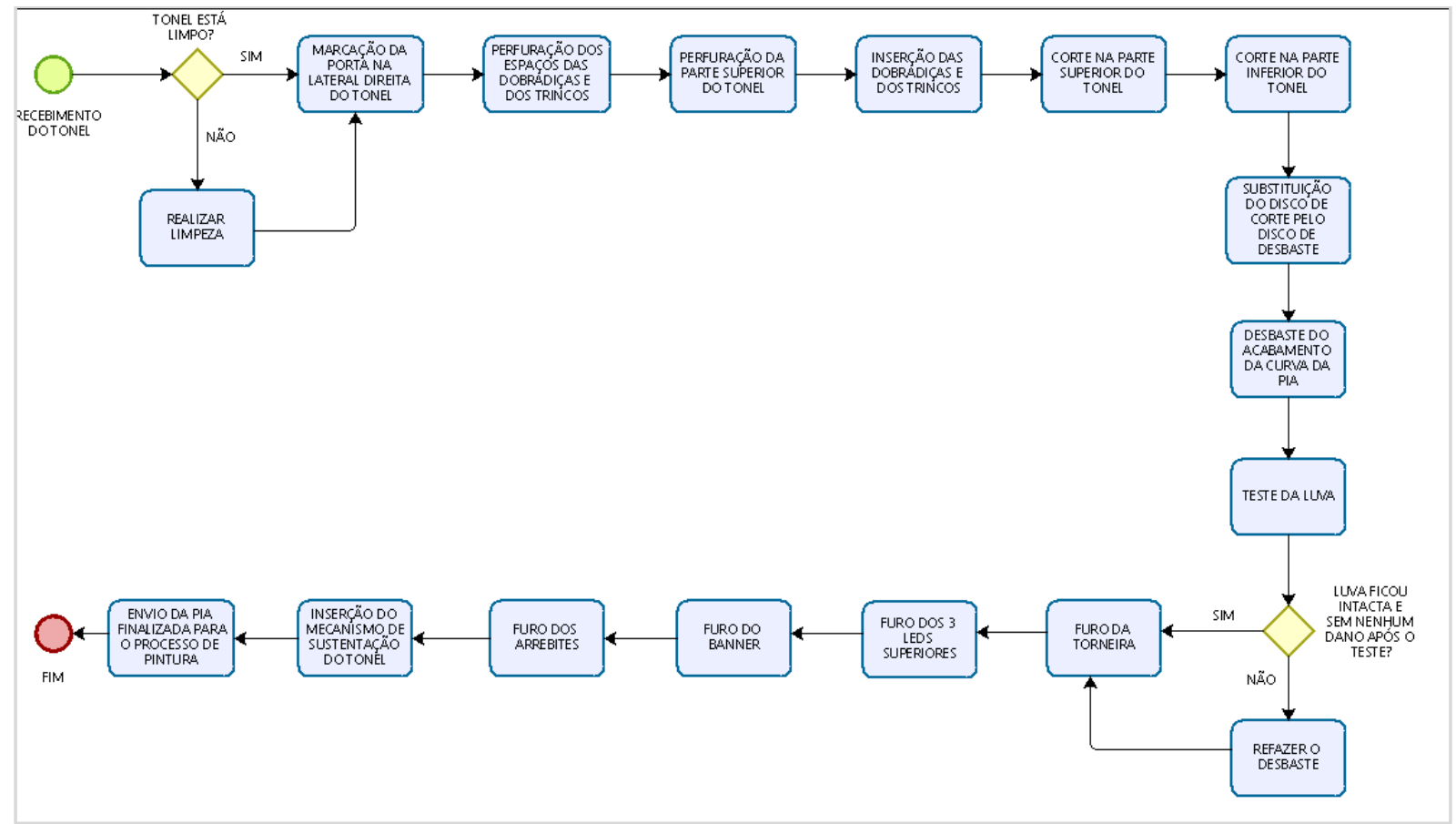

FIGURA 6 - Processo de fabricação. Fonte: Os autores 
O projeto da pia portátil ajudou a disseminar os cuidados perante ao novo coronavírus em locais públicos. As primeiras 20 unidades produzidas foram instaladas junto aos postos de triagem de possíveis contaminados, em Pelotas, além de outros espaços de concentração de pessoas, tais como terminais de ônibus e acessos aos diversos campus da universidade. A Figura 7 (a) (b) (c) mostram algumas ações onde o produto foi exposto e as notícias vinculadas.

\section{Higienizador Eco-Mãos: projeto do CEng auxiliará no retorno de atividades presenciais}

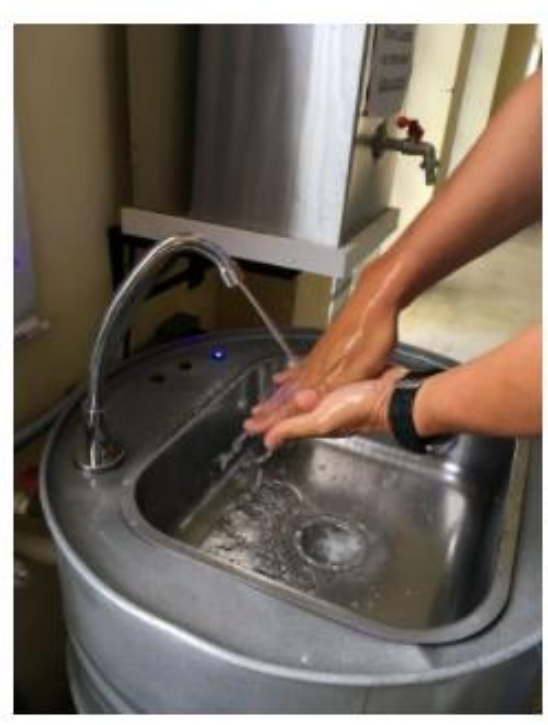

O retorno das atividades acadêmicas presenciais na Universidade Federal de Pelotas ainda não tem uma data certa, mas já conta com um grande aliado para a prevenção do contágio da covid-19. E o melhor: é um projeto desenvolvido por estudantes, professores e técnicos do Centro de Engenharias.

O higienizador Eco-Mãos consiste em uma pia móvel feita a partir de um material industrial reaproveitado. A adaptação é realizada com uma cuba, uma torneira, compartimento para armazenamento de sabão e, dependendo da sua versão, depósito de água potável e de água já utilizada.

Inspirado em um projeto semelhante desenvolvido pela Universidade Federal de Rio Grande (FURG), a primeira versão do equipamento foi produzida ainda nas primeiras semanas da pandemia. Até então, a ideia é que a pia fosse portátil, para ser utilizada em estruturas temporárias destinadas a atendimento de pacientes com suspeitas de covid-19 ou em outros pontos de grande concentração de pessoas. Por isso, a primeira versão não dependia de eletricidade externa ou entrada e saída de água e esgoto.

(a)
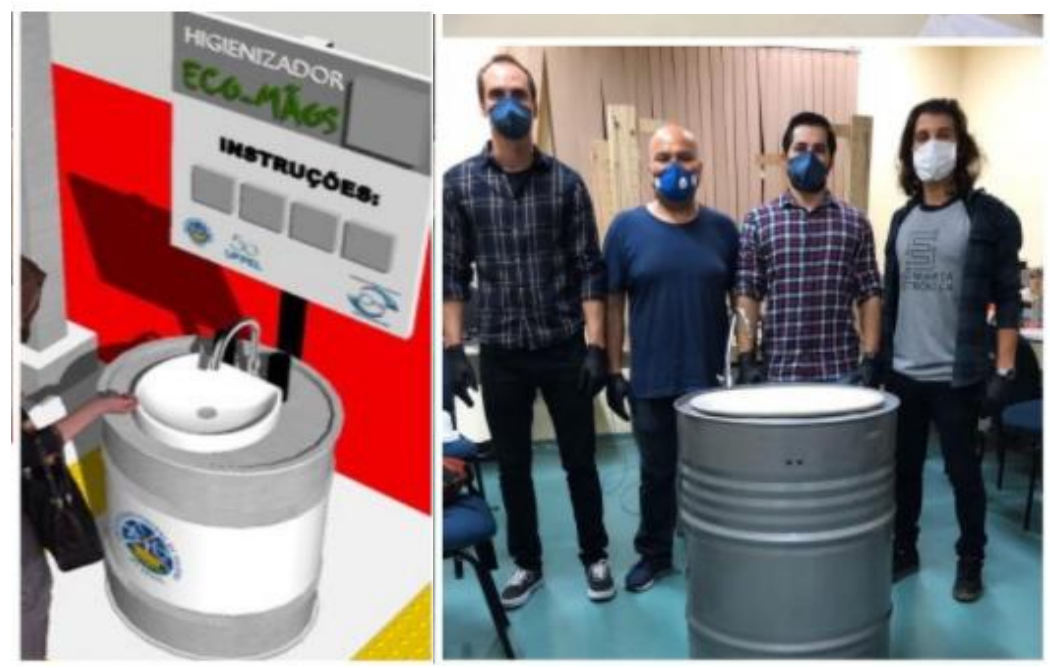

(b) 


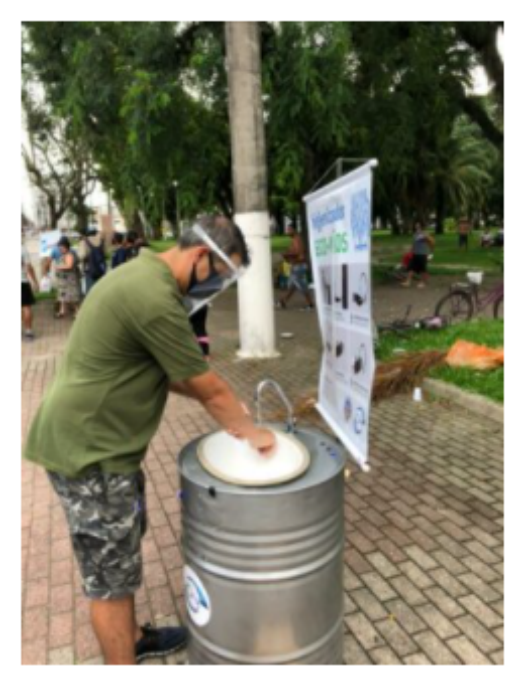

Automatizada, econômica e ecoeficiente

A pia portátil foi projetada para ser um sistema híbrido: ele funciona conectado às redes hidráulicas e também pode ser abastecido manualmente. 0 equipamento projetado na FURG traz dois recipientes de igual volume, um para água limpa e outro para efluentes, e ainda um reservatório para sabão líquido. A capacidade é de 60 litros. 0 sistema desenvolvido faz 0 acionamento por proximidade. Primeiramente, ele lança o sabão líquido e, então, a torneira aciona o jato d’água também com a resposta de um sensor. A pessoa que o utiliza não precisa abrir ou fechar a torneira, evitando possibilidade de contaminação. 0 resultado é uma pia portátil automatizada, econômica e ecoeficiente.

O Eco-Mãos é um projeto de extensão da UFPel que tem como foco principal a aplicação de conhecimentos de engenharia para desenvolver tecnologias e sistemas que ajudem na mitigação dos problemas sanitários decorrentes do COVID-19. 0 projeto do desenvolvimento destes sistemas de higienização nasce do interesse de um grupo de alunos, egressos, técnicos e professores de gerar soluções práticas que ajudem as comunidades na mitigação de doenças através do uso de mecanismos de higienização automáticos que estejam disponíveis em locaischave de alto fluxo de pessoas. Busca, ainda, que através de componentes didáticos possam ensinar os passos corretos de higienização e assim disseminar este ensinamento nas comunidades.

(c)

FIGURA 7 - Fotos do produto. Fonte: (a) Higienizador eco-mão projeto (2020) (b) CEng-ufpel desenvolve higienizador (2020) (c) Higienizador de mão adaptado (2021).

\section{CONCLUSÃO}

Dentre dos desafios encontrados na concepção e construção das pias está a necessidade de contar com equipes multidisciplinares de trabalho que consigam desenvolver sistemas e novas tecnologias acordes às necessidades das comunidades e às mudanças sociais e comportamentais que traz os desafios produzidos pela Covid-19. Adicionalmente, é importante ressaltar que os protótipos foram desenvolvidos de forma a flexibilizar o acréscimo de novos dispositivos e tecnologias que melhorem o funcionamento, assim como flexibilidade para poder ser adaptados às características físicas do entorno no qual serão instalados. O presente projeto deverá gerar resultados que contribuirão em uma série de pontos, dentre os quais é possível citar: apoiar as ações da UFPel para o combate do coronavírus (Covid-19); proporcionar à sociedade a oportunidade para educação para saúde, por meio da promoção de bons hábitos como lavar as mãos de forma habitual; envolver e motivar os docentes e discentes dos cursos do CEng e da UFPel para o desenvolvimento de projetos em equipes multidisciplinares, proporcionar o desenvolvimento de um equipamento que seja sustentável, econômico de fácil uso e manutenção. Destaca-se que pretende-se ainda executar etapas para realizar o aproveitamento da água após o uso da lavagem das mãos 
(reuso), professores da área de engenharia ambiental estão estudando sistemas para realizar a filtragem e reuso.

\section{REFERÊNCIAS}

(a) HIGIENIZADOR eco-mãos: projeto CEng auxiliará no retorno de atividades presenciais. 2020. Disponível em: https://ccs2.ufpel.edu.br/wp/2020/12/09/higienizador-eco-maos-projeto-do-ceng-auxiliara-no-retorno-deatividades-presenciais/. Acesso em: 4 abr. 2021.

(b) CENG/UFPEL desenvolve higienizador eco-mãos. 2020. Disponível em: https://wp.ufpel.edu.br/ceng/cengufpel-desenvolve-higienizador-eco-maos/. Acesso em: 4 abr. 2021.

(c) HIGIENIZADOR de mãos adaptados pela UFPel é disponibilizado a pessoa em condições de vulnerabilidade. 2021. Disponível em: https://ccs2.ufpel.edu.br/wp/2021/02/18/higienizador-de-maos-adaptadopela-ufpel-e-disponibilizado-a-pessoas-em-condicoes-de-

vulnerabilidade/?fbclid=IwAR2PnKngX9uXffCf78SZzIQvCfoW1JClwwpaCWXIMVp8X2nrD1_gdRK-gzs.

Acesso em: 4 abr. 2021.

ARRUDA, A. Design \& inovação social. São Paulo: Blucher, 2017. DOI: 10.5151/9788580392647.

Conselho Federal de Enfermagem. Informações sobre o Coronavírus. Disponível em: http://biblioteca.cofen.gov.br/informacoes-sobre-coronavirus/. Acesso: 4 abr. 2021.

ETZKOWITZ, H.; ZHOU, C. Hélice tríplice: inovação e empreendedorismo universidade-indústria-governo. Inovação. Estudos Avançados, v. 31, n.90, p. 23-48. May-Aug 2017, $23-48$.

GIL, A. C. Como elaborar projetos de pesquisa. Rio de Janeiro: Atlas 2017.

IGNATIUS, J.; LEEN, J.Y.A.; RAMAYAH, T.; HIN, C.K.; JANTAN, M. The Impact of technological learning on NPD outcomes: the moderating effect of project complexity. Technovation, v.32, P. 452-463, 2012.

KAHN, K.B.; BARCZAK, G.; NICHOLAS, J.; LEDWITH, A.; PERKS, H. An Examination of new product development best practice. Journal of Product Innovatio Management, v. 29, N. 2, P. 180-192, 2012.

KANDT, A., PICKSHAUSB, T., FLEISCHERA, K., SCHMITT, R. A New Model to Ascertain Product Maturity in Product Development Processes in: Procedia CIRP 50 26th CIRP Design Conference, 2016, pp. 173-178.

PROENÇA, A.; LACERDA, D.; ANTUNES JÚNIOR, J. A.V.; TÁVORA JUNIOR, J. L.; SALERNO, M. S. Gestão da inovação e competitividade no Brasil: da teoria para a prática. Porto Alegre: Bookman, 2015.

ROSSI, M.; TERZI, S. CLIMB: maturity assessment model for design and engineering processes. International Journal of Product Lifecycle Management, v. 10, n. 1, p. 20-43, 2017.

ROZENFELD, H.; FORCELLINI, F. A.; AMARAL, D. C.; TOLEDO, J. C. Gestão de desenvolvimento de produtos: uma referência para melhoria do processo. São Paulo: Saraiva, 2006.

SALERNO, M. S. Políticas de inovação no Brasil: desafios de formulação, financiamento e implantação. in: COUTINHO, D. R.; FOSS, M.C.; MOUALLEM, P.S.B. Inovação no Brasil: avanços e desafios jurídicos e institucionais. São Paulo: Blucher, 2017.Cap.3, p. 79-96. 